\title{
Specific olfactory neurons and glomeruli are associated to differences in behavioral responses to pheromone components between two Helicoverpa species
}

OPEN ACCESS

Edited by:

Martin Giurfa,

Centre National de la Recherche Scientifique-Université Paul

Sabatier-Toulouse III, France

Reviewed by:

Shannon Bryn Olsson,

National Center for Biological

Sciences, India

Sylvia Anton,

Institut National de la Recherche

Agronomique, France

Nina Deisig,

Institut National de la Recherche

Agronomique, France

*Correspondence:

Chen-Zhu Wang

Institute of Zoology, Chinese Academy of Sciences, 1 Beichen West Road,

Chaoyang, Beijing 100101, China czwang@ioz.ac.cn

Received: 08 May 2015

Accepted: 20 July 2015

Published: 04 August 2015

Citation:

Wu H, Xu M, Hou C, Huang L-Q,

Dong J-F and Wang C-Z (2015)

Specific olfactory neurons and glomeruli are associated to differences in behavioral responses to pheromone

components between two Helicoverpa species.

Front. Behav. Neurosci. 9:206. doi: 10.3389/fnbeh.2015.00206

\author{
Han $W u^{1}$, Meng $X u^{1}$, Chao Hou ${ }^{1}$, Ling-Qiao Huang ${ }^{1}$, Jun-Feng Dong ${ }^{1,2}$ and \\ Chen-Zhu Wang ${ }^{1 *}$
}

\footnotetext{
'State Key Laboratory of Integrated Management of Pest Insects and Rodents, Institute of Zoology, Chinese Academy of Sciences, Beijing, China, ${ }^{2}$ Department of Plant Protection, Forestry College, Henan University of Science and Technology, Luoyang, China
}

Sex pheromone communication of moths helps to understand the mechanisms underlying reproductive isolation and speciation. Helicoverpa armigera and Helicoverpa assulta use (Z)-11-hexadecenal (Z11-16:Ald) and (Z)-9-hexadecenal (Z9-16:Ald) as pheromone components in reversed ratios, $97: 3$ and 5:95, respectively. $H$. armigera also produces trace amount of (Z)-9-tetradecenal (Z9-14:Ald) in the sex pheromone gland, but $H$. assulta does not. Wind tunnel studies revealed that the addition of small amounts (0.3\%) of Z9-14:Ald to the main pheromone blend of $H$. armigera increased the males' attraction, but at higher doses (1\%,10\%) the same compound acted as an inhibitor. In $H$. assulta, Z9-14:Ald reduced male attraction when presented as $1 \%$ to the pheromone blend, but was ineffective at lower concentrations (0.3\%). Three types (A-C) of sensilla trichodea in antennae were identified by single sensillum recording, responding to Z11-16:Ald, Z9-14:Ald, and both Z9-16:Ald and Z9-14:Ald, respectively. Calcium imaging in the antennal lobes (ALs) revealed that the input information of the three chemicals was transmitted to three units of the macroglomerular complex (MGC) in ALs in both species: a large glomerulus for the major pheromone components, a small one for the minor pheromone components, and a third one for the behavioral antagonists. The type A and C neurons tuned to Z11-16:Ald and Z9-16:Ald had a reversed target in the MGC between the two species. In H. armigera, low doses (1, 10 $\mu$ g) of Z9-14:Ald dominantly activated the glomerulus which processes the minor pheromone component, while a higher dose $(100 \mu \mathrm{g})$ also evoked an equal activity in the antagonistic glomerulus. In H. assulta, instead, Z9-14:Ald always strongly activated the antagonistic glomerulus. These results suggest that Z9-14:Ald plays different roles in the sexual communication of two Helicoverpa species through activation of functionally different olfactory pathways.

Keywords: behavior, sex pheromone, olfactory sensory neurons, calcium imaging, antennal lobe 


\section{Introduction}

To mate successfully, male moths have to correctly identify sex pheromones released by conspecific females. In most moth species, the pheromones contain two or a few chemical components in a species-specific ratio (Arn et al., 1992; Mustaparta, 1997; Berg et al., 2014). Behavioral studies have demonstrated that both individual conspecific and heterospecific sex pheromone components may act as behavioral antagonists when they are released at inappropriate ratios and rates (Vetter and Baker, 1984; Vickers et al., 1991; Baker, 2008). However, the olfactory mechanisms of the antagonist effect remains poorly understood.

Sex pheromone components are first detected by olfactory sensory neurons (OSNs) in the sensilla trichodea on antennae of male moths (Hansson et al., 1987; Kaissling et al., 1989; Cossé et al., 1998; Baker et al., 2004). Then the pheromone signals are transmitted to the first olfactory processing center, the antennal lobe $(\mathrm{AL})$. In the $\mathrm{AL}$, the OSNs expressing the same odor receptor converge to the same glomerulus (Gao et al., 2000; Vosshall et al., 2000). Male Heliothine moths possess a special and large macroglomerular complex (MGC), which usually consists of three or four glomeruli and is dedicated to processing the intra- and interspecific pheromone information, as demonstrated by electrophysiological recording combined with staining of AL neurons (Hansson et al., 1991; Vickers et al., 1998; Berg et al., 2005). For several Heliothine species, two essential sex pheromone components of respective pheromone blends are represented in two separate MGC glomeruli, and at least one other glomerulus of the MGC is used to process known behavioral antagonists (Hansson et al., 1995; Vickers et al., 1998; Vickers and Christensen, 2003; Lee et al., 2006a,b; Zhao and Berg, 2010).

The two sympatric and closely-related species, Helicoverpa armigera and Helicoverpa assulta both use (Z)-11-hexadecenal (Z11-16:Ald) and (Z)-9-hexadecenal (Z9-16:Ald) as essential sex pheromone components but in opposite ratios (Kehat et al., 1980; Cork et al., 1992). Behavioral studies have demonstrated that the binary blends of Z11-16:Ald and Z9-16:Ald at their pheromone gland ratios (97:3 in H. armigera, 7:93 in H. assulta) are sufficient for eliciting male attraction behavior in the corresponding species (Zhao et al., 2006; Ming et al., 2007). Besides Z11-16:Ald and Z9-16:Ald, about 0.25-1.5\% (Z)-9-tetradecenal (Z9-14:Ald) was found in the female pheromone gland of $H$. armigera but not in that of H. assulta (Kehat and Dunkelblum, 1990; Zhang et al., 2012). There are conflicting results on the effect of addition of Z9-14:Ald to the pheromone blends in previous studies. Field tests in Australia demonstrated that captures of $H$. armigera males were significantly increased with the addition of 2-5\% Z914:Ald to Z11-16:Ald (Rothschild, 1978). In China, behavioral data showed that $0.3 \%$ Z9-14:Ald in combination with binary pheromone blends trapped more $H$. armigera males in field tests (Zhang et al., 2012). However, wind tunnel experiments and field traps in Israel showed that 5-10\% Z9-14:Ald in the synthetic pheromone blend significantly inhibited the attraction behavior of H. armigera males (Gothilf et al., 1978; Kehat and Dunkelblum, 1990). In the Korean population of $H$. assulta the addition of
Z9-14:Ald interrupted the pheromone-mediated communication resulting in a significant reduction in trap catches (Boo et al., 1995).

In this study, we first investigated the behavioral responses of the two Helicoverpa species to a series of synthetic blends that contained different amounts of Z9-14:Ald added to the binary pheromone blends of the corresponding species. In order to explain how Z9-14:Ald plays different roles in the pheromone communication of two Helicoverpa species, we further characterized the related OSNs in antennae and response patterns in antennal lobes, and revealed different olfactory pathways activated by Z9-14:Ald in males of the two species.

\section{Materials and Methods}

\section{Insects}

For H. armigera and H. assulta are agricultural pests in China, no specific permission was required to collect any of these samples. All insect samples were treated according to the guideline of State Key Laboratory of Integrated Management of Pest Insects and Rodents, Institute of Zoology, Chinese Academy of Sciences. $H$. armigera and $H$. assulta larvae were collected from tobacco field in Zhengzhou, Henan Province, China, and reared in the laboratory on an artificial diet (Wu and Gong, 1997). Each year, some individuals of the second generation from the field are introduced into the laboratory colonies. The successive generations were maintained in an environmental chamber at $26 \pm 1{ }^{\circ} \mathrm{C}$ with a relative humidity of $40 \%-60 \%$ on a $16 \mathrm{~L}: 8 \mathrm{D}$ photoperiod. Pupae of different sex were separated daily. Adult male moths used in the physiological and behavioral experiments were $2-5$ days old.

\section{Chemicals}

Z11-16:Ald, Z9-16:Ald, and Z9-14:Ald were purchased from Shin-Estu company (Tokyo, Japan). The compounds were further purified to $>98 \%$ by column chromatography on silica gel. Series of dilutions of the pheromones in redistilled paraffin oil (Analytical grade, Fluka) were stored in $2 \mathrm{ml}$ glass vials (Agilent, Technologies, USA) at $-20^{\circ} \mathrm{C}$.

\section{Behavioral Tests}

A wind tunnel was used to investigate the role of Z9-14:Ald in the attraction behavior of $H$. armigera and $H$. assulta males. In $H$. armigera, the following odor sources were tested: (1) hexane, used as the negative control for it was the solvent of pheromone components; (2) binary mixture of Z11-16:Ald and Z9-16:Ald at the pheromone gland ratio of 97:3, used as the positive control for $H$. armigera (PC1); (3) PC1 + 0.3\% Z914:Ald; (4) PC1 + 0.5\% Z9-14:Ald; (5) PC1 + 1\% Z9-14:Ald; (6) PC1 + 10\% Z9-14:Ald. In H. assulta, hexane was also used as the negative control and the binary mixture of Z11-16:Ald and Z9-16:Ald at the pheromone gland ratio of 5:95 as the positive control ( $\mathrm{PC} 2)$. We also tested the males responses to both PC2 + 0.3\% Z9-14:Ald and PC2 + 1\% Z9-14:Ald. Each odor source was loaded on a rubber septum. The loaded dosage for the positive control was $1 \mathrm{mg}$ ( $10 \mu \mathrm{l}$ of $100 \mu \mathrm{g} / \mu \mathrm{l}$ solution). The proportion of Z9-14:Ald was relative to the amount of PC1 or 
PC2. For example, PC1+ 0.3\% Z9-14:Ald in H. armigera means $1 \mathrm{mg}$ of the binary mixture of Z11-16:Ald and Z9-16:Ald at 97:3 in combination with $3 \mu \mathrm{g}$ Z9-14:Ald. Different amounts of Z914:Ald were added to reach the established proportions. In each experiment, 9-15 male moths were tested on any given day. The order of treatments in each replicate was randomized. At least three replicates were run.

Behavioral observations for males of the two Helicoverpa species were performed in a wind tunnel as described previously (Zhao et al., 2006). Briefly, 2-5 days old virgin males were exposed during their scotophase (4-6 h) in a clear plexiglass wind tunnel $(2.5 \mathrm{~m}$ long, $1 \mathrm{~m}$ wide, $1 \mathrm{~m}$ high). The males were transferred to the wind tunnel room ca. $45 \mathrm{~min}$ prior to observations in order for them to become acclimated to the room conditions $\left(0.3-0.5 \mathrm{~m} / \mathrm{s}\right.$ wind velocity, $24 \pm 2{ }^{\circ} \mathrm{C}, 40-60 \%$ relative humidity, $0.3 \mathrm{Lux}$ red light). The males responses were categorized according to the following stereotyped behavior (1) Flight: taking off from release cage; (2) Upwind: flying at the height of lure and showing characteristic zig-zag paths toward pheromone source; (3) Close: continuing upwind behavior and flying within $10 \mathrm{~cm}$ of pheromone source; (4) Landing: contacting the lure.

\section{Physiological Characterization of the OSNs Responding to Z11-16:Ald, Z9-16:Ald and Z9-14:Ald, and their Corresponding Glomeruli}

We used the cut-sensillum technique in vivo to physiologically characterize the selectivity of OSNs in male antennae of $H$. armigera and $H$. assulta to Z11-16:Ald, Z9-16:Ald, and Z914:Ald. Paraffin oil was used as the solvent of these chemicals because it induced no response in both SSR and calcium imaging experiments. The responding OSNs were located on the flagellar segments number 25-60 in the antenna. To determine the selectivity of OSNs, we used the dosage of $100 \mu \mathrm{g}$ of each compound ( $10 \mu \mathrm{l}$ of $10 \mu \mathrm{g} / \mu \mathrm{l}$ solutions) as test stimulus. The dosage chosen was based on the dose response curves of OSNs in our previous work (Wu et al., 2013), in which about $10 \mu \mathrm{g} \mathrm{Z11-}$ 16:Ald or Z9-16:Ald dissolved in hexane could induce $50 \%$ of each OSN maximal firing rate. We did a preliminary experiment which indicated that $10 \mu \mathrm{g}$ Z11-16:Ald or Z9-16:Ald dissolved in hexane $(10 \mu \mathrm{l})$ induced an equal response with $100 \mu \mathrm{g}$ of corresponding compounds in paraffin oil $(10 \mu \mathrm{l})$. Paraffin oil was used as a control. We also tested the dose responses of Z9-14:Ald with different doses $(0.1,1,10,100,1000 \mu \mathrm{g}$, each diluted in $10 \mu \mathrm{l}$ paraffin oil) in both species. The cross-adaptation experiments between Z9-16:Ald and Z9-14:Ald were carried out to determine whether the different spiking activity could be attributed to the same neuron or to the different neurons in the same sensillum (Cossé et al., 1998; Baker et al., 2004; Domingue et al., 2010).

In vivo calcium imaging was used to reveal the functional relationship between the OSNs tuned to Z11-16:Ald, Z9-16:Ald, and Z9-14:Ald and the targeted MGC subunits in the ALs of $H$. armigera and $H$. assulta males. Paraffin oil was used as control. The order of the stimuli was randomized. Because males showed to be sensitive to the addition of trace amount of Z9-14:Ald in behavior experiments, this compound was used in three doses $(1,10,100 \mu \mathrm{g}$ each diluted in $10 \mu \mathrm{l}$ paraffin oil) for optical recordings. The methods how to recognize the activated glomeruli were described in detail in our previous work (Wu et al., 2013). Briefly, we first identified the activated area from false-color coded images in the calcium imaging. Then we superimposed the response pattern of the odorant $(>50 \%$ activity) on gray scale images of the AL by ImageJ software with $\mathrm{Z}$ project treatment. Because the AL atlas of the two Helicoverpa species are available (Berg et al., 2002; Skiri et al., 2005), we identified the activated glomerulus of the MGC according to their position and outline.

\section{Single Sensillum Recording}

The cut-sensillum technique was conducted as described earlier (Kaissling, 1974; Baker et al., 2004). Briefly, the male moth was first placed inside a $1-\mathrm{ml}$ pipette tip with the narrow end cut to ensure the head to pass through. Then the head with protruding antennae was fixed on a fastening device. A tungsten electrode was inserted into one of the compound eyes to serve as a ground connection. The sensilla were randomly selected mainly from the 25th to the 60th flagellar segment. After cutting the sensillum tip with home-made forceps, the spiking activities of OSNs were collected through an $\mathrm{Ag}-\mathrm{AgCl}$ recording electrode connected to an amplifier. For each compound, $10 \mu \mathrm{l}$ of $10 \mu \mathrm{g} / \mu \mathrm{l}$ solution were placed on a filter paper strip $(0.7 \mathrm{~cm} \times 2.5 \mathrm{~cm})$ held in a Pasteur pipette (15 cm long).

A continuous stream of purified and humidified air was directed on the antenna $(12.5 \mathrm{ml} / \mathrm{s})$ from the outlet of a steel tube (i.d. $6 \mathrm{~mm}$, length $15 \mathrm{~cm}$ ) positioned $2 \mathrm{~cm}$ away. Test odors were injected into the air stream using a stimulus flow-controller (CS-55, Syntech), which generated air pulses through the odor cartridge at a flow rate of $10 \mathrm{ml} / \mathrm{s}$. The stimulus time was $200 \mathrm{~ms}$ and the sensilla were grouped according to the response profiles of OSNs. The signals from the recording electrode were sent to a programmable signal-recording and output controller (IDAC-4, Syntech, Hilversum, Netherlands). Autospike version 3.4 software (Syntech) was used for both recording and data analysis. In the same sensillum, action potentials from OSNs were declared to be "larger" or "smaller" on the base of their spike size. Action potential frequencies (spikes/s) were calculated by counting the number of spikes occurring during the first $200 \mathrm{~ms}$ of the spike train initiated by a stimulus puff. The crossadaptation experiments between Z9-16:Ald and Z9-14:Ald were conducted using the method described previously (Cossé et al., 1998; Baker et al., 2004; Domingue et al., 2010).

\section{In vivo Calcium Imaging}

Animal preparations were performed as reported in the literature (Hansson et al., 2003; Galizia and Vetter, 2005). After dissection, a calcium-sensitive dye CaGR-1-AM (Molecular Probes, Eugene, OR, USA) was used to stain the brain. Then the insect was placed into a dark room at $12^{\circ} \mathrm{C}$. One hour later, the brain was thoroughly rinsed with Ringer solution (Christensen and Hildebrand, 1987) and ready for imaging. The stimuli were applied with the same method used for single sensillum recording.

Imaging data were collected with a Till-Photonics imaging system (Till Photonics, Germany) in combination with an 
epifluorescent microscope (Olympus BX-51WI, Tokyo, Japan) equipped with a $20 \times$ (NA 0.95 , Olympus) water immersion objective. A stimuli sequence contained 40 frames with a sampling rate of $4 \mathrm{~Hz}$. Exposure time was $200 \mathrm{~ms}$ for each frame and stimulation was set at frame 12 and lasted for $500 \mathrm{~ms}$. To increase signal to noise ratio, images were binned $2 \times$ on chip (to $320 \times 240$ pixels).

Raw data were filtered using spatial and time median filters to remove "salt and pepper" noise (Galizia and Vetter, 2005). Background fluorescence (F) was defined as the mean fluorescence of frames 2-11, recorded just before onset of stimulation. For the false color images, the fluorescence change of each frame was expressed as $\Delta \mathrm{F} / \mathrm{F}$. In time traces, $\mathrm{Fn} / \mathrm{F}$ ( $n=1-40$ ) was first expressed for the ratio of each frame against background and then followed by a smooth treatment (smooth, 30 frames). $\Delta \mathrm{F} / \mathrm{F}$ of each frame was defined as the difference between the signals before and after smoothing, i.e., $\Delta \mathrm{F} / \mathrm{F}=\mathrm{Fn} / \mathrm{F}-\mathrm{Fn} / \mathrm{F}$ (smooth, 30 frames). Next, each pixel was assigned a value that was then converted into a color. Smooth treatment can reduce noise but not remove pertinent signals. For quantitative analysis of the response intensity, activity foci with averaged area of 177 pixels were chosen to represent the glomerular response after recognition of targeted glomerulus. The mean of three sequential frames at the signal's maximum was taken as the amplitude of odor-induced responses.

\section{Data Analyses}

In wind tunnel experiment, percents of males performing sequential behaviors were subjected to Chi-square test of independence with Yates' continuity correction $(P<0.05)$. Data of single sensillum recording were analyzed by the OneWay ANOVA for analysis of variance, and the least significant difference (LSD) test was used for means multiple comparisons $(P<0.05)$. In calcium imaging, data were acquired by the software Till-vision (Till photonics) and further analyzed by software Image (NIH, USA) and custom-made programs in MATLAB (The Math Works, Inc). Paired $t$-tests were used to compare the sensitivity between subunits of MGC $(P<0.01)$.

\section{Results}

\section{Behavioral Response of Males to Different Synthetic Blends}

In the wind tunnel, males of $H$. armigera were highly attracted to the binary pheromone blend (Z11-16:Ald and Z9-16:Ald) at the gland ratio (97:3) and showed robust mate-seeking behavior (Figure 1A). The presence of Z9-14:Ald in the ternary blend at a relatively low ratio $(0.3 \%)$ significantly increased the males landing behavior. Increasing Z9-14:Ald to $0.5 \%$ had no significant effect on males' behavioral responses. Instead, higher doses (1\% and $10 \%)$ of Z9-14:Ald in the ternary blends did not affect taking flight, but inhibited the males upwind and close searching behavior. Therefore, Z9-14:Ald could act as agonist or antagonist to $H$. armigera males, depending on its concentration (Figure 1A).

Males of $H$. assulta also exhibited stereotypical attraction behavior to the binary pheromone blend (Z11-16:Ald and Z916:Ald) at gland ratio (Figure 1B), and the addition of $0.3 \%$ Z9-14:Ald in the pheromone blend did not significantly affect male attraction. However, in the presence of 1\% Z9-14:Ald, $H$. assulta males were less attracted to the ternary blend (Figure 1B).

\section{Olfactory Sensory Neurons (OSNs) Tuned to Z11-16:Ald, Z9-16:Ald, and Z9-14:Ald}

In our SSR experiments, we detected three distinctly different response profiles in both $H$. armigera and $H$. assulta (Figures 2, 3). Here, the three types of sensilla are named according to what has been reported for other Heliothine species (Baker et al., 2004). The type A sensilla contained OSNs responding only to Z11-16:Ald, those of type B were specifically tuned to Z9-14:Ald, while the OSNs of type C sensilla could be activated by both Z9-16:Ald and Z9-14:Ald (Figures 2, 3).

In $H$. armigera, out of 451 responding sensilla, 399 were of type A (88\%), 9 were of type B (2\%), and 43 were of type C (10\%) (Figure 2). In the type C Z9-14:Ald and Z9-16:Ald evoked distinct responses at the dosage of $100 \mu \mathrm{g}$ (Figure 2B).

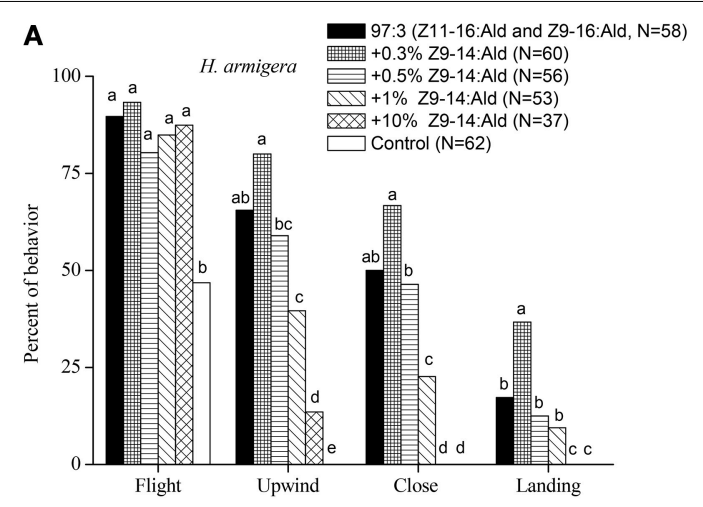

FIGURE 1 | Behavioral responses males of Helicoverpa armigera (A) and $\boldsymbol{H}$. assulta $(B)$ to a series of synthetic blends. The blends contained varying dosages of Z9-14:Ald relative to the binary mixture (Z11-16:Ald and

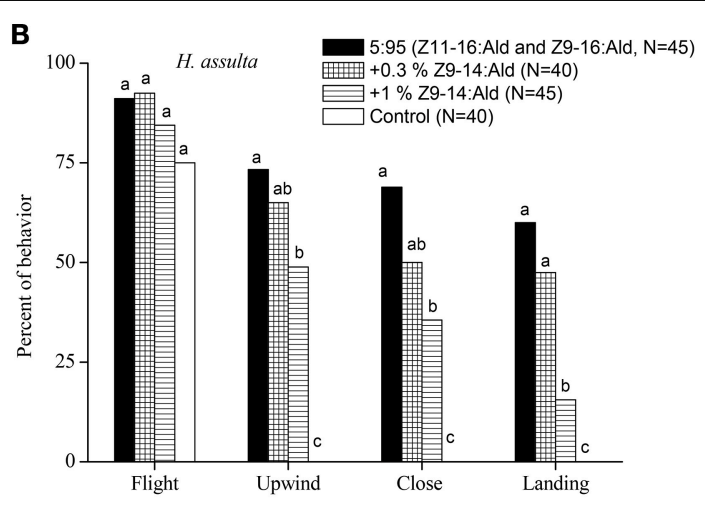

Z9-16:Ald at gland ratios of each species). Hexane was used as control. Symbols in the same behavioral category bearing different letters are significantly different (Chi-square test, $P<0.05$ ). 


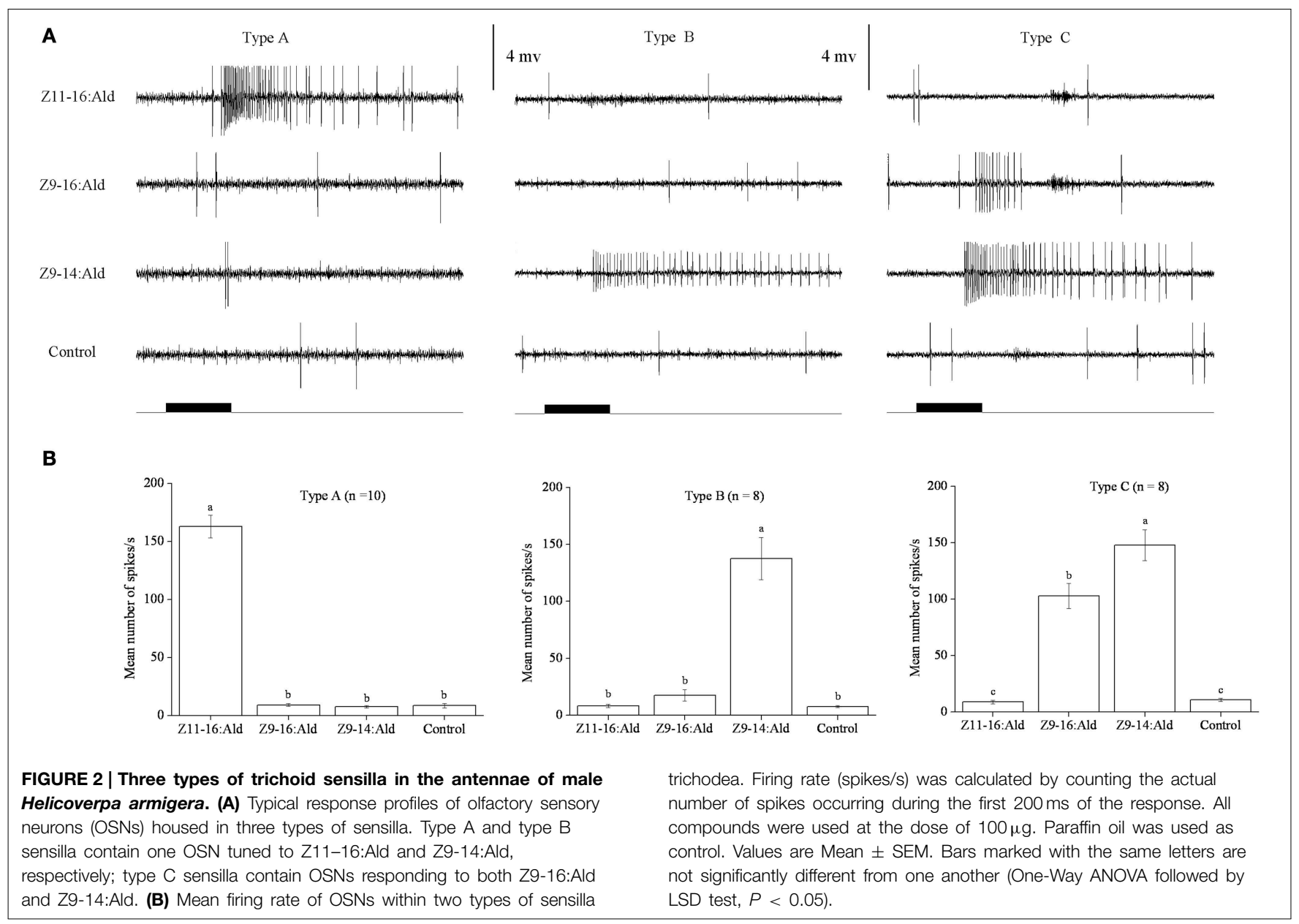

Based on spike amplitude, it appears that the same OSN in the type $\mathrm{C}$ sensilla responds to both compounds (Figure 2A). The dose response curve of Z9-14:Ald in the type C sensilla showed an increase in firing rate in a dose-related manner and from $10 \mu \mathrm{g}$ Z9-14:Ald induced significant spiking activities (Figure 4A).

However, we found two different response profiles in type $\mathrm{C}$ sensilla when stimulated with Z9-16:Ald and Z-11-hexadecenol (Z11-16:OH), suggesting there are at least two different OSNs in this type of sensilla (Figure S1 in Supplementary Material). In the following cross-adaptation experiments, we found that regardless of whether Z9-16:Ald or Z9-14:Ald was the first stimulus, the OSN was partially adapted by the second stimulation with the same odorant (Figure S2 in Supplementary Material). A similar pattern was found when a first stimulation with Z9-14:Ald was followed by one with Z9-16:Ald (Figure S2 in Supplementary Material). However, one OSN was not adapted when we first stimulated with Z9-16:Ald and then with Z9-14:Ald, indicating the presence of two different OSNs responding to Z9-14:Ald in the type $\mathrm{C}$ sensillum of $H$. armigera (Figure S2 in Supplementary Material).

In $H$. assulta, out of 182 responding sensilla, 11 and 10 were classified as type A (6\%) and B (5\%), respectively, while 161 belonged to type C (89\%) (Figure 3). Based on spike amplitude, we could clearly distinguish two OSNs in each sensillum of type C (Figure 3A). The first with the larger spike amplitude responded to both Z9-16:Ald and Z9-14:Ald, with a stronger signal for the first compound when the stimuli were used at a dose of $100 \mu \mathrm{g}$ (Figure 3B). The second OSN responded only to Z9-14:Ald (Figure 3). The dose-response curves showed that the dosage for Z9-14:Ald, which elicited response in the large-spiking OSNs was 100 times higher than that for the smaller-spiking one (Figure 4B).

\section{MGC Glomeruli Activated by Z9-14:Ald in Two Helicoverpa Species}

Based on the AL atlas of $H$. armigera and $H$. assulta (Berg et al., 2002; Skiri et al., 2005), we were able to identify the activated MGC subunits according to their position and outline. The activity patterns (frontal view) shown in Figure 5 were evoked by stimulation with $100 \mu \mathrm{g}$ of Z11-16:Ald, Z9-16:Ald, and Z914:Ald.

In $H$. armigera, the largest glomerulus (cumulus) was activated by Z11-16:Ald and the posterior dorsomedial unit (Dm-p) by Z9-16:Ald (Figure 5A), which is consistent with our previous results (Wu et al., 2013). Both the Dm-p and the anterior 

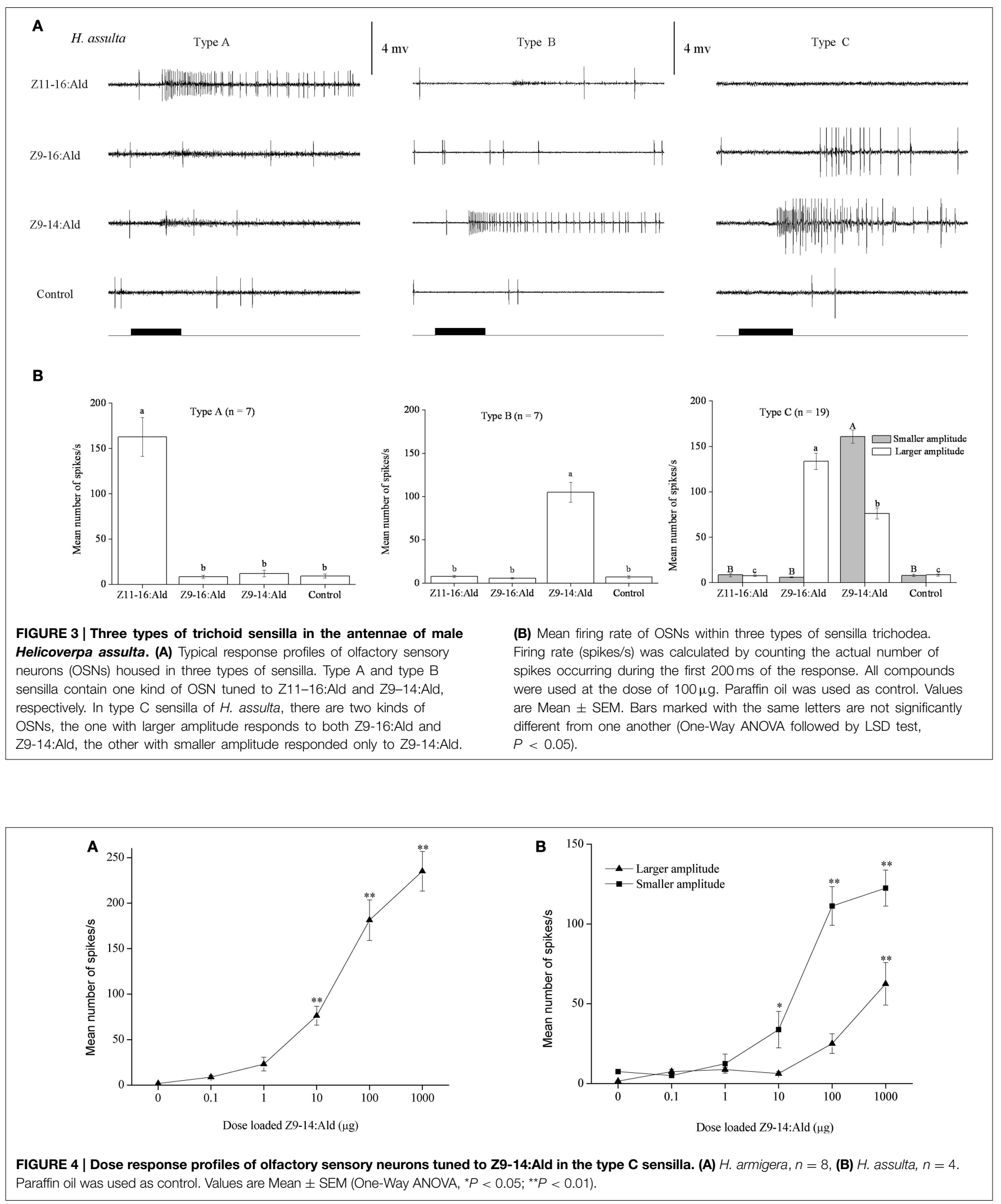


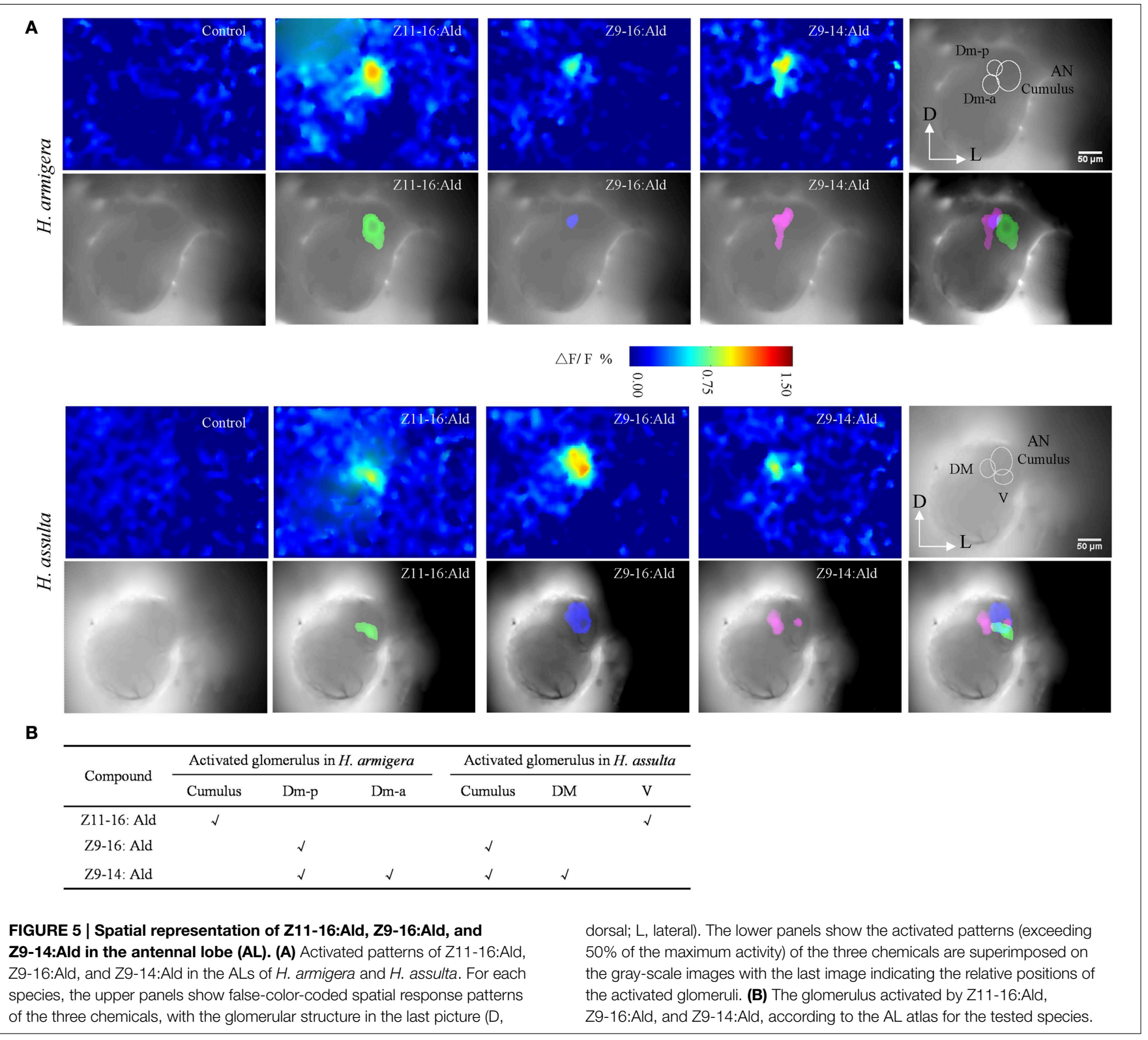

dorsomedial unit (Dm-a) were simultaneously activated by Z914:Ald (Figure 5A) and the spatial representation in the AL was reproducible among different individuals.

In $H$. assulta, the cumulus was activated by Z9-16:Ald and the ventral unit (V) by Z11-16:Ald. Z9-14:Ald evoked a strong response in the dorsomedial unit (DM) and a weak response in the cumulus (Figure 5A). In some preparations, Z9-14:Ald did not induce any response in the cumulus.

Higher concentrations of Z9-14:Ald induced correspondingly stronger responses in ALs of both Helicoverpa species (Figure 6). In H. armigera, Z9-14:Ald activated both the Dm-p and the Dm-a in the MGC of the AL (Figures 5, 6). The Dm-p was also activated by Z9-16:Ald, which is the secondary sex pheromone component of $H$. armigera. The Dm-p was significantly more sensitive than the Dm-a to Z9-14:Ald at the dosages of $1 \mu \mathrm{g}$ and $10 \mu \mathrm{g}$. However, the Dm-p and the Dm-a showed similar activities to Z9-14:Ald at the dosage of $100 \mu \mathrm{g}$ (Figure 6A).

In $H$. assulta, 1 or $10 \mu \mathrm{g}$ of Z9-14:Ald only evoked responses in the DM, but when used at the dose of $100 \mu \mathrm{g}$ this compound, besides inducing a strong response in the DM also produced a weak signal in the cumulus (Figures 5A, 6B). Statistical analysis of the results showed that the DM was much more sensitive than the cumulus to Z9-14:Ald all across the range of tested doses (Figure 6B).

\section{Discussion}

Z11-16:Ald and Z9-16:Ald are the essential components of pheromone blends for both $H$. armigera and $H$. assulta but in reverse ratios, 97:3 and 5:95, respectively. In the present 


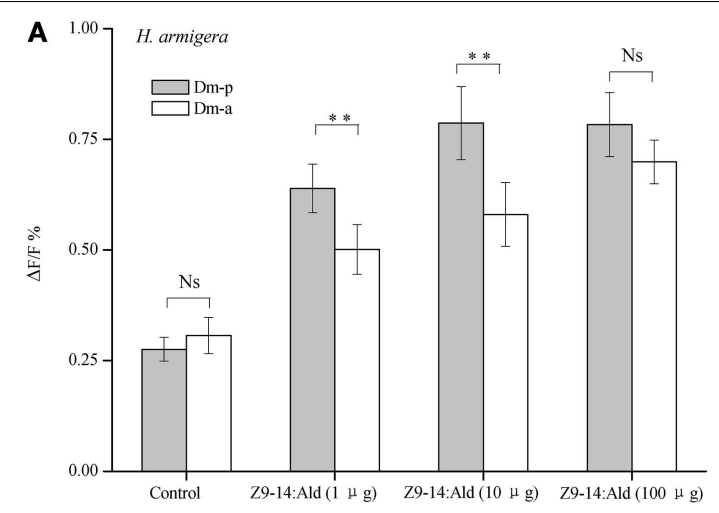

FIGURE 6 | Glomerular activities induced by Z9-14:Ald at different dosages in the two Helicoverpa species. The tested dosages were 1, 10, $100 \mu \mathrm{g}$. (A) Comparison of glomerular activities between the Dm-p and the

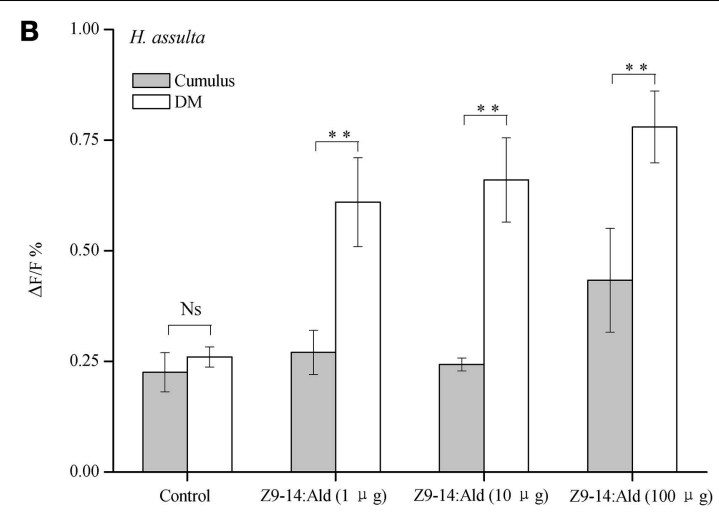

Dm-a in $H$. armigera $(n=9)$. (B) Comparison of glomerular activities between the DM and the cumulus in $H$. assulta $(n=6)$. Values are Mean $\pm \mathrm{SEM}$ (Paired $t$-test, ${ }^{\star \star} P<0.01$, Ns No significant difference). study, Z9-14:Ald acted as an agonist when minor amounts were added to the binary pheromone blend of $H$. armigera, but as an antagonist at a higher levels. For H. assulta, Z9-14:Ald acted as an antagonist especially when presented with higher concentration. Based on the activated OSNs and related glomeruli, we found that the agonist and the antagonist effect of Z9-14:Ald involved different olfactory pathways in the two species.

\section{OSNs and Related Glomeruli Mediating Attraction and Aversion}

Sex pheromones are first detected by OSNs on the antennae and then the signals are sent to the MGC of the $\mathrm{AL}$ via a labeled-line system, as exemplified in many moth species (Christensen and Hildebrand, 1987; Vickers and Christensen, 2003; Berg et al., 2005; Lee et al., 2006a,b). Comparative and phylogenetic studies have demonstrated that several Heliothine moth species are closely-related and share a common organization and information processing in the olfactory system. The MGC is generally composed of 3-4 glomeruli, two of them are used to process sex pheromones and at least one glomerulus is dedicated to processing known behavioral antagonists (Vickers et al., 1998; Berg et al., 2005; Baker, 2008).

In H. armigera, both Z9-16:Ald and Z9-14:Ald activated Dmp, while Z9-14:Ald also activated Dm-a (Figure 5). Based on our SSR results and the hypothesis that the OSNs expressing the same odorant receptor converge onto the same glomerulus, we predict that there are two compartmentalized OSNs in type C sensillum of $H$. armigera, in which one is tuned to both Z9-16:Ald and Z9-14:Ald and another only to Z9-14:Ald (Figures S1, S2 in Supplementary Material and Figure 7). This topography of type $\mathrm{C}$ in $H$. armigera is similar to that of the closely-related species Helicoverpa zea (Cossé et al., 1998; Lee et al., 2006a). In H. assulta, Z9-14:Ald induced a strong response in the DM and a weak response in the cumulus (Figures 5, 6), in agreement with the observation that the large-spike OSN of type C is tuned to both Z9-16:Ald and Z9-14:Ald, while the small-spike OSN responds only to Z9-14:Ald (Figures 3, 7).
Each of the two principal sex pheromone components activated single glomeruli of the MGC in $H$. armigera and $H$. assulta (Wu et al., 2013). In H. armigera, Z11-16:Ald and Z9-16:Ald activate the cumulus and the Dm-p of the MGC, respectively (Figure 5), while in $H$. assulta, Z11-16:Ald and Z916:Ald evoked a response in the ventral unit and in the cumulus of the MGC, respectively (Figure 5). Based on the structure and functional significance of MGC glomeruli in these two species (Berg et al., 2002; Skiri et al., 2005), we confirm that the Dm-a in $H$. armigera and the DM in $H$. assulta are involved in processing behavioral antagonists (Figure 7). H. zea, a most closely-related species with $H$. armigera, has a similar MGC structure in which the Dm-a is used to process behavioral antagonists (Lee et al., 2006a).

Z9-14:Ald activates the glomeruli processing behavioral antagonists, Dm-a in $H$. armigera and DM in $H$. assulta, but why does Z9-14:Ald act as agonist in $H$. armigera and increases males' attraction at lower dosages? Dose responses of Z9-14:Ald in the AL of $H$. armigera show that the Dm$\mathrm{p}$ is more sensitive than the Dm-a when presented with low dosages of Z9-14:Ald (1 and $10 \mu \mathrm{g}$, Figure 6A), but both respond with similar intensity to higher doses of the same stimulus $(100 \mu \mathrm{g}$, Figure 6A). Therefore in $H$. armigera, low dosages of Z9-14:Ald in the pheromone blends act as an agonist and activate the more sensitive glomerulus, the Dm-p, which is responsible for the principal pheromone component Z9-16:Ald, but does not reach the threshold for activating the Dm-a responsible for behavioral antagonists. Instead, higher dosages of Z9-14:Ald activate both the Dm-p and the Dm-a, leading to the interruption of attraction behavior (Figure 7). For H. assulta, the antagonistic DM was significantly more sensitive than the cumulus to Z9-14:Ald at any tested dosage (Figure 6B). Such a difference in sensitivity of the two glomeruli could be due to the difference in sensitivity of two OSNs responding to Z914:Ald in the type C sensilla (Figure 4B). Previous behavioral and neurophysiological data demonstrated that the DM is involved in processing behavioral antagonists (Boo et al., 1995; Berg et al., 2005; Zhao and Berg, 2010). This can explain why the addition 


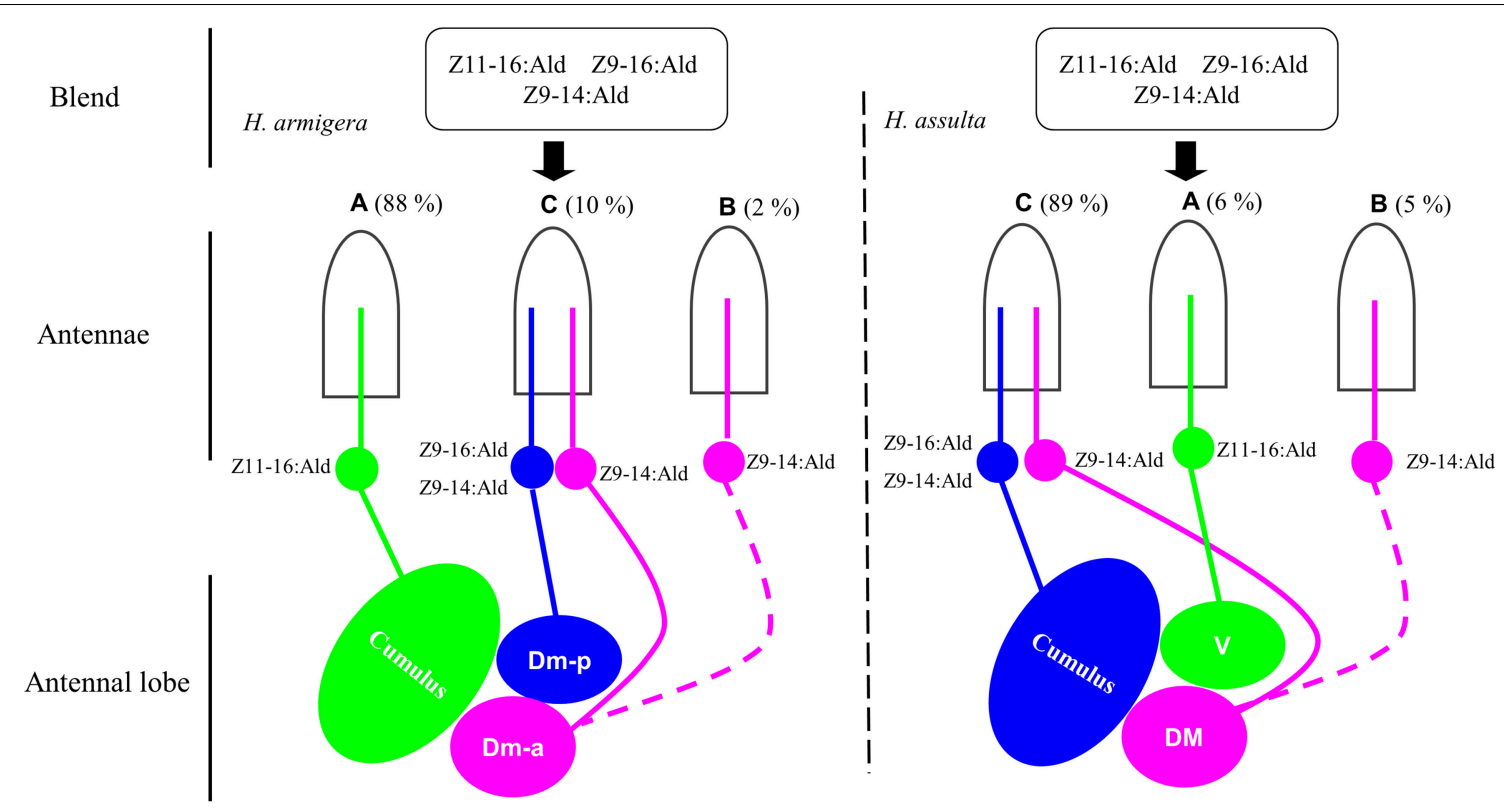

FIGURE 7 | Drawing based on different combinations of special olfactory pathways encoding different behaviors. The picture drawn based on the results from single sensillum recording, calcium imaging and behavioral tests. Green: the neurons tuned to Z11-16:Ald and the target glomerulus. Blue: the neurons tuned to
Z9-16:Ald and Z9-14:Ald and the target glomerulus. Pink: the neurons tuned to Z9-14:Ald and the target glomerulus. Hatched line: the speculated pathway. Dm-p, posterior dorsomedial unit; Dm-a, anterior dorsomedial unit; DM, dorsomedial unit; V, ventral unit. of Z9-14:Ald to the pheromonal blend results in the antagonism of upwind flight in H. assulta males (Figure 7). In Drosophila species, it has been demonstrated that the same compounds at different concentrations activate different neurons and related glomeruli and finally elicit different behaviors, thus confirming that different stimulus intensities can evoke distinct perception (Semmelhack and Wang, 2009; Lin et al., 2013; Zhang et al., 2013).

\section{The Abundance of OSNs Tuned to Z9-14:Ald on the Antennae}

In general, when the OSNs tuned to sex pheromone components are in different sensilla, the abundance of the related sensilla corresponds to the ratio of the components in the pheromonal blend (Cossé et al., 1998; Baker et al., 2004; Wu et al., 2013). However, although Z9-14:Ald is not a sex pheromone component in $H$. assulta, and not the principal one in $H$. armigera, we found that the sensilla responding to this compound account for about $94 \%$ in $H$. assulta (including 5\% type B sensilla and $89 \%$ type $C$ sensilla) and $12 \%$ (2\% type B and $10 \%$ type $\mathrm{C}$ sensilla) in $H$. armigera. This characteristic seems to be common among heliothine moths. In fact, there are about 29 and $26 \%$ sensilla housing OSNs tuned to the nonpheromone component Z9-14:Ald in H. zea and Heliothis subflexa, respectively (Cossé et al., 1998; Baker et al., 2004). Z9-14:Ald is an essential pheromone component for NorthAmerican Heliothis virescens (Klun et al., 1980), but it is an antagonist and decreases male attraction for the sympatric moth H. zea (Shaver et al., 1982; Vickers et al., 1991). Z9-14:Ald is also a sex pheromone component of Heliothis peltigera (Dunkelblum and Kehat, 1989). These phenomenon suggests that Z9-14:Ald plays an important role in pheromone communication and also in behavioral isolation of the sympatric heliothine species.

Z9-14:Ald may be an evolutionarily old sex pheromone component of ancestral heliothine species, and thus the OSNs tuned to Z9-14:Ald would be also primitive in this group of insects. During speciation such OSNs could adapt to other related chemicals with maintenance of their original trait. Molecular phylogenetics suggest that $H$. virescens and $H$. peltigera using Z914:Ald as sex pheromone components are ancestral compared to $H$. armigera and $H$. assulta (Cho et al., 1995, 2008), in which the OSNs of type C sensilla keep a higher sensitivity to Z9-14:Ald, meanwhile respond to their pheromone component, Z9-16:Ald (Figures 2, 3).

\section{Concluding Remarks}

Our study clarifies that Z9-14:Ald serves as both agonist and antagonist in sex pheromone communication of $H$. armigera depending on its relative ratio, but acts as an antagonist in $H$. assulta. Such behavioral shifts in the two species result from that Z9-14:Ald activates different specific combinations of OSNs and related glomeruli in the MGC. Functional divergence in pheromone-related olfactory pathways helps to shape pheromone perception, contributing to understand the mechanisms of reproductive isolation and speciation. In the antennal lobe of moth species, the projection neurons receive 
input from OSNs and send output to the higher brain centers, such as the mushroom body and the lateral horn. Future research will focus on the mechanism by which these centers generate different behaviors.

\section{Author Contributions}

HW: Designed the experiments, provided and analyzed experimental data, and wrote the manuscript. MX: Provided experimental data. $\mathrm{CH}$ : Provided experimental data. $\mathrm{LQH}$ and JFD: Provided materials and technical support on experiments. CZW: Conceived the project, advised with experimental procedures, analyzed data, and wrote the manuscript.

\section{Acknowledgments}

We thank C. Giovanni Galizia of University of Konstanz in Germany for advices in the optical recording, Jun Zhao of the Institute of Biophysics of the Chinese Academy of Sciences for assistance in data analyses and our colleague Lin Yang for technical help. We also thank three reviewers for their valuable comments and suggestions. This work was supported by the Strategic Priority Research Program of the Chinese Academy of Sciences (Grant No. XDB11010300),

\section{References}

Arn, H., Tóth, M., and Priesner, E. (1992). List of Sex Pheromones of Lepidoptera and Related Attractants. 2nd Edn. Montfavet: International Organization for Biological Control; West Palearctic Regional Section.

Baker, T. C., Ochieng, S. A., Cossé, A. A., Lee, S. G., Todd, J. L., Quero, C., et al. (2004). A comparison of responses from olfactory receptor neurons of Heliothis subflexa and Heliothis virescens to components of their sex pheromone. J. Comp. Physiol. A 190, 155-165. doi: 10.1007/s00359-003-0483-2

Baker, T. C. (2008). Balanced olfactory antagonism as a concept for understanding evolutionary shifts in moth sex pheromone blends. J. Chem. Ecol. 34, 971-981. doi: $10.1007 / \mathrm{s} 10886-008-9468-5$

Berg, B. G., Almaas, T. J., Bjaalie, J. G., and Mustaparta, H. (2005). Projections of male-specific receptor neurons in the antennal lobe of the oriental tobacco budworm moth, Helicoverpa assulta: a unique glomerular organization among related species. J. Comp. Neurol. 486, 209-220. doi: 10.1002/cne.20544

Berg, B. G., Galizia, C. G., Brandt, R., and Mustaparta, H. (2002). Digital atlases of the antennal lobe in two species of tobacco budworm moths, the oriental Helicoverpa assulta (Male) and the American Heliothis virescens (Male and female). J. Comp. Neurol. 446, 123-134. doi: 10.1002/cne.10180

Berg, B. G., Zhao, X. C., and Wang, G. (2014). Processing of pheromone information in related species of Heliothine moths. Insects 5, 742-761. doi: $10.3390 /$ insects5040742

Boo, K. S., Park, K. C., Hall, D. R., Cork, A., Berg, B. G., and Mustaparta, H. (1995). (Z)-9-Tetradecenal - a potent inhibitor of pheromone-mediated communication in the oriental tobacco budworm moth, Helicoverpa assulta. J. Comp. Physiol. A 177, 695-699. doi: 10.1007/BF00187628

Cho, S., Mitchell, A., Mitter, C., Regier, J., Matthews, M., and Robertson, R. (2008). Molecular phylogenetics of heliothine moths (Lepidoptera: Noctuidae: Heliothinae), with comments on the evolution of host range and pest status. Syst. Entomol. 33, 581-594. doi: 10.1111/j.1365-3113.2008.00427.x

Cho, S. W., Mitchell, A., Regier, J. C., Mitter, C., Poole, R. W., Friedlander, T. P., et al. (1995). A highly conserved nuclear gene for low level phylogenetics elongation factor-1-alpha recovers morphology-based tree for Heliothine moths. Mol. Biol. Evol. 12, 650-656. the National Natural Science Foundation of China (Grant No. 31130050), and National Basic Research Program of China (Grant No.2012CB114105) and State Key Laboratory of Integrated Management of Pest Insects and Rodents (Chinese IPM1409). The funders had no role in study design, data collection and analysis, decision to publish, or preparation of the manuscript.

\section{Supplementary Material}

The Supplementary Material for this article can be found online at: http://journal.frontiersin.org/article/10.3389/fnbeh. 2015.00206

Figure S1 | Two types of neurons colocalized within type $\mathbf{C}$ sensilla in Helicoverpa armigera. (A) Response profile of type $C$ sensilla to Z9-16:Ald $(100 \mu \mathrm{g}), \mathrm{Z11}-16: \mathrm{OH}(100 \mu \mathrm{g})$, and Z9-14:Ald $(1,10,100 \mu \mathrm{g})$. Paraffin oil was used as control. The horizontal black bar indicates stimulus duration of $200 \mathrm{~ms}$. (B) The wave forms of spikes sampled during $10 \mathrm{~s}$ of spontaneous activity (same neuron as in A responding to control) indicates two neuron types. (C) Amplitude classification of firing patterns during $10 \mathrm{~s}$ showing that Z9-16:Ald activated the larger-spike neuron, $\mathrm{Z11}-16: \mathrm{OH}$ activated the smaller-spike neuron, while Z9-14:Ald at the dosage $100 \mu \mathrm{g}$ activated both neurons.

Figure S2 | Examples of traces generated during cross-adaptation stimulation of an OSN in a $\boldsymbol{H}$. armigera Type $\mathbf{C}$ sensillum. Horizontal bar denotes stimulus delivery time of $100 \mathrm{~ms}$. The interval between two stimulations is about $350 \mathrm{~ms}$. All stimuli loadings were of $100 \mu \mathrm{g}$.

Christensen, T. A., and Hildebrand, J. G. (1987). Male-specific, sex pheromoneselective projection neurons in the antennal lobes of the moth Manduca sexta. J. Comp. Physiol. A 160, 553-569. doi: 10.1007/BF00611929

Cork, A., Boo, K. S., Dunkelblum, E., Hall, D. R., Jeerajunga, K., Kehat, M., et al. (1992). Female sex pheromone of oriental tobacco budworm, Helicoverpa assulta (Guénee) (Lepidoptera, Noctuidae) identification and field testing. J. Chem. Ecol. 18, 403-418. doi: 10.1007/BF00994240

Cossé, A. A., Todd, J. L., and Baker, T. C. (1998). Neurons discovered in male Helicoverpa zea antennae that correlate with pheromone-mediated attraction and interspecific antagonism. J. Comp. Physiol. A 182, 585-594. doi: $10.1007 / s 003590050205$

Domingue, M. J., Musto, C. J., Linn, C. E., Roelofs, W. L., and Baker, T. C. (2010). Homology of olfactory receptor neuron response characteristics inferred from hybrids between Asian and European corn borer moths (Lepidoptera: Crambidae). J. Insect. Physiol. 56, 73-80. doi: 10.1016/j.jinsphys.2009.09.005

Dunkelblum, E., and Kehat, M. (1989). Female sex pheromone component of Heliothis peltigera (Lepidoptera, Noctuidae) chemical identification from gland extracts and male response. J. Chem. Ecol. 15, 2233-2245. doi: 10.1007/BF01014112

Galizia, C. G., and Vetter, R. S. (2005). "Optical methods for analyzing odourevoked activity in the insect brain," in Methods in Insect Sensory Neuroscience, ed T. A. Christensen (Roca Raton,FL: CRC Press), 349-392.

Gao, Q., Yuan, B., and Chess, A. (2000). Convergent projections of Drosophila olfactory neurons to specific glomeruli in the antennal lobe. Nat. Neurosci. 3, 780-785. doi: 10.1038/75753

Gothilf, S., Kehat, M., Jacobson, M., and Galun, R. (1978). Sex attractants for male Heliothis armigera (Hbn). Cell. Mol. Life Sci. 34, 853-854. doi: 10.1007/BF01939662

Hansson, B. S., Almaas, T. J., and Anton, S. (1995). Chemical communication in Heliothine moths.5. Antennal lobe projection patterns of pheromone-detecting olfactory receptor neurons in the male Heliothis virescens (Lepidoptera, Noctuidae). J. Comp. Physiol. A 177, 535-543.

Hansson, B. S., Carlsson, M. A., and Kalinovà, B. (2003). Olfactory activation patterns in the antennal lobe of the sphinx moth, Manduca sexta. J. Comp. Physiol. A 189, 301-308. doi: 10.1007/s00359-003-0403-5 
Hansson, B. S., Christensen, T. A., and Hildebrand, J. G. (1991). Functionally distinct subdivisions of the macroglomerular complex in the antennal lobe of the male Sphinx moth Manduca sexta. J. Comp. Neurol. 312, 264-278. doi: $10.1002 /$ cne. 903120209

Hansson, B. S., Löfstedt, C., and Roelofs, W. L. (1987). Inheritance of olfactory response to sex pheromone components in Ostrinia nubilalis. Naturwissenschaften 74, 497-499. doi: 10.1007/BF00447935

Kaissling, K. E., Hildebrand, J. G., and Tumlinson, J. H. (1989). Pheromone receptor cells in the male moth Manduca sexta. Arch. Insect. Biochem. Physiol. 10, 273-279. doi: 10.1002/arch.940100403

Kaissling, K. E. (1974). "Sensory transduction in insect olfactory receptors," in Biochemistry of Sensory Functions, ed L. Jaenicke (Berlin: Springer), 243-273.

Kehat, M., and Dunkelblum, E. (1990). Behavioral responses of male Heliothis armigera (Lepidoptera: Noctuidae) moths in a flight tunnel to combinations of components identified from female sex pheromone glands. J. Insect. Behav. 3, 75-83. doi: 10.1007/BF01049196

Kehat, M., Gothilf, S., Dunkelblum, E., and Greenberg, S. (1980). Field evaluation of female sex pheromone components of the cotton bollworm, Heliothis armigera. Entomol. Exp. Appl. 27, 188-193. doi: 10.1111/j.15707458.1980.tb02963.x

Klun, J. A., Bierlleonhardt, B. A., Plimmer, J. R., Sparks, A. N., Primiani, M., Chapman, O. L., et al. (1980). Sex pheromone chemistry of the female tobacco budworm moth, Heliothis virescens. J. Chem. Ecol. 6, 177-183. doi: 10.1007/BF00987536

Lee, S. G., Carlsson, M. A., Hansson, B. S., Todd, J. L., and Baker, T. C. (2006a). Antennal lobe projection destinations of Helicoverpa zea male olfactory receptor neurons responsive to heliothine sex pheromone components. J. Comp. Physiol. A. 192, 351-363. doi: 10.1007/s00359-005-0071-8

Lee, S. G., Vickers, N. J., and Baker, T. C. (2006b). Glomerular targets of Heliothis subflexa male olfactory receptor neurons housed within long trichoid sensilla. Chem. Senses 31, 821-834. doi: 10.1093/chemse/bj1025

Lin, H. H., Chu, L. A., Fu, T. F., Dickson, B. J., and Chiang, A. S. (2013). Parallel neural pathways mediate $\mathrm{CO}_{2}$ avoidance responses in Drosophila. Science 340, 1338-1341. doi: 10.1126/science.1236693

Ming, Q. L., Yan, Y. H., and Wang, C. Z. (2007). Mechanisms of premating isolation between Helicoverpa armigera (Hübner) and Helicoverpa assulta (Guenée) (Lepidoptera: Noctuidae). J. Insect. Physiol. 53, 170-178. doi: 10.1016/j.jinsphys.2006.11.007

Mustaparta, H. (1997). "Olfactory coding mechanisms for pheromone and interspecific signal information in related moth species," in Insect Pheromone Research: New Directions, ed R. T. Cardé (New York, NY: Chapman and Hall), 144-163.

Rothschild, G. H. L. (1978). Attractants for Heliothis armigera and Heliothis punctigera. J. Aust. Entomol. Soc. 17, 389-390. doi: 10.1111/j.1440-6055.1978.tb01514.x

Semmelhack, J. L., and Wang, J. W. (2009). Select Drosophila glomeruli mediate innate olfactory attraction and aversion. Nature 459, 218-223. doi: 10.1038 /nature 07983

Shaver, T. N., Lopez, J. D., and Harstack, A. W. (1982). Effects of pheromone components and their degradation products on the response of Heliothis spp to traps. J. Chem. Ecol. 8, 755-762. doi: 10.1007/BF00988316
Skiri, H. T., Rø, H., Berg, B. G., and Mustaparta, H. (2005). Consistent organization of glomeruli in the antennal lobes of related species of Heliothine moths. J. Comp. Neurol. 491, 367-380. doi: 10.1002/cne.20692

Vetter, R. S., and Baker, T. C. (1984). Behavioral responses of male Heliothis zea (Lepidoptera: Noctuidae) moths in sustained flight tunnel to combinations of 4 compounds identified from female sex pheromone gland. J. Chem. Ecol. 10, 193-202. doi: 10.1007/BF00987848

Vickers, N. J., and Christensen, T. A. (2003). Functional divergence of spatially conserved olfactory glomeruli in two related moth species. Chem. Senses. 28, 325-338. doi: 10.1093/chemse/28.4.325

Vickers, N. J., Christensen, T. A., and Hildebrand, J. G. (1998). Combinatorial odor discrimination in the brain: Attractive and antagonist odor blends are represented in distinct combinations of uniquely identifable glomeruli. J. Comp. Neurol. 400, 35-56.

Vickers, N. J., Christensen, T. A., Mustaparta, H., and Baker, T. C. (1991). Chemical communication in Heliothine moths III. Flight behavior of male Helicoverpa $z e a$ and Heliothis virescens in response to varying ratios of intraspecific and interspecific sex pheromone components. J. Comp. Physiol. A. 169, 275-280.

Vosshall, L. B., Wong, A. M., and Axel, R. (2000). An olfactory sensory map in the fly brain. Cell 102, 147-159. doi: 10.1016/S0092-8674(00)00021-0

Wu, H., Hou, C., Huang, L. Q., Yan, F. S., and Wang, C. Z. (2013). Peripheral coding of sex pheromone blends with reverse ratios in two Helicoverpa species. PLoS ONE 8:e70078. doi: 10.1371/journal.pone.0070078

Wu, K. J., and Gong, P. Y. (1997). A new and practical artificial diet for the cotton bollworm. Entomol. Sin. 4, 277-282.

Zhang, J. P., Salcedo, C., Fang, Y. L., Zhang, R. J., and Zhang, Z. N. (2012). An overlooked component: (Z)-9-tetradecenal as a sex pheromone in Helicoverpa armigera. J. Insect. Physiol. 58, 1209-1216. doi: 10.1016/j.jinsphys.2012.05.018

Zhang, Y. L. V., Ni, J. F., and Montell, C. (2013). The molecular basis for attractive salt-taste coding in Drosophila. Science 340, 1334-1338. doi: $10.1126 /$ science. 1234133

Zhao, X. C., and Berg, B. G. (2010). Arrangement of output information from the 3 macroglomerular units in the Heliothine moth Helicoverpa assulta: Morphological and physiological features of male-specific projection neurons. Chem. Senses. 35, 511-521. doi: 10.1093/chemse/bjq043

Zhao, X. C., Yan, Y. H., and Wang, C. Z. (2006). Behavioral and electrophysiological responses of Helicoverpa assulta, $H$. armigera (Lepidoptera: Noctuidae), their F-1 hybrids and backcross progenies to sex pheromone component blends. J. Comp. Physiol. A. 192, 1037-1047. doi: 10.1007/s00359-006-0141-6

Conflict of Interest Statement: The authors declare that the research was conducted in the absence of any commercial or financial relationships that could be construed as a potential conflict of interest.

Copyright (c) $2015 \mathrm{Wu}, \mathrm{Xu}, \mathrm{Hou}$, Huang, Dong and Wang. This is an open-access article distributed under the terms of the Creative Commons Attribution License (CC $B Y)$. The use, distribution or reproduction in other forums is permitted, provided the original author(s) or licensor are credited and that the original publication in this journal is cited, in accordance with accepted academic practice. No use, distribution or reproduction is permitted which does not comply with these terms. 